Submission ID: 43858

\title{
Geological Model of Novoportovskoe Field for Geosteering
}

A.V. Karnaukhov* (Gazpromneft NTC), D.O. Mishina (Gazpromneft NTC), D.A. Reshetnikov (Gazpromneft NTC), L.R. Samigullin (Gazpromneft NTC)

\section{SUMMARY}

Novoportovskoye field is one of the most perspective object of the Company, which contains high oil reserves. In 2015 has been started full-scale drilling on main production targets - NP2-3, NP4, NP5, J2-6. On line navigation requires geological model that has good ability of prediction and shouldn't change in zones situated far from drilling region. Geological modelling performed in Shlumberger Petrel 15.4. Five algorithms were examined. Suggesting algorithm is using Truncated Gaussian Simulation with 3d trends made with Trend Modelling. Suggesting algorithm provides better ability of prediction and makes geological model more sustainable. 
Построение геологической модели Новопортовского месторождения под цели сопровождения бурения

А.В. Карнаухов* (ООО «Газпромнефть НТЦ»), Д.О. Мишина (ООО «Газпромнефть НТЦ»), Д.А. Решетников (OOO «Газпромнефть НТЦ»), Л.Р. Самигуллин (ООО «Газпромнефть НТЦ»).

\section{Введение}

На разных этапах жизни проекта к геологической модели, описывающей строение продуктивных пластов, предъявляются разные требования. На этапе концептуального моделирования необходимо проанализировать всю имеющуюся информацию, включая представления о генезисе продуктивных пластов, учесть ее при построении модели, и корректно оценить запасы углеводородов и риски. Это объемная и трудоемкая работа, однако при переводе проекта на полномасштабную разработку появляются новые, более специфические потребности, которые не всегда в состоянии удовлетворить даже такая сложная модель.

Когда геологическая модель начинает использоваться для оперативного сопровождения бурения, возникает необходимость выполнения как минимум двух условий:

- Высокая прогнозная способность модели. Фактические свойства пласта и показатели работы скважин, такие как эффективная мощность пласта, эффективная проходка ГС, ФЕС пласта, стартовые дебиты, темпы падения должны максимально соответствовать ожидаемым.

- Стационарность результата. После обновления модели на новые скважины не должно происходить изменений в зонах, удаленных от региона бурения. Подобные необоснованные изменения - например, появление пропластка неколлектора там, где он раньше был, могут привести к изменению планируемых показателей работы скважины - увеличить срок прорыва газа, увеличить темп падения добычи за счет снижения вертикальной проницаемости разреза.

Кроме того, алгоритм построения модели должен быть оптимизирован для оперативного обновления на результаты бурения новых скважин.

\section{Метод}

В ходе построения геологической модели было рассмотрено несколько вариантов реализации поставленных задач. Было необходимо, чтобы модель:

- Отвечала концептуальным представлениям о геологическом строении продуктивных пластов. Для этого при построении куба фаций предполагается использовать карты, построенные по результатам седиментационного анализа керна.

- Соответствовала скважинным данным. Пласт достаточно плотно разбурен, поэтому статистика геологических параметров по модели (гистограммы литологии, пористости) должна соответствовать скважинам (вертикальные и субвертикальные траектории).

- Не имела необоснованных изменений параметров пласта, противоречащих концептуальной модели. Необходимо исключить появление в межскважинном пространстве локальных изменений параметров (эффективная мощность пласта, ФЕС), не имеющих объяснения с точки зрения концептуальной модели.

- Обладала высокой прогнозной способностью.

- Обеспечивала стационарный результат.

Моделирование осуществлялось в ПК Schlumberger Petrel 2015.4. Для построения дискретных параметров (кубы фаций, литологии) из инструментария программы для тестирования было выбрано несколько методов: 
- Sequential Indicator Simulation (SIS) с использованием ГСР и 2Д трендов. Предыдущий вариант модели строился этим методом, который позволяет использовать в качестве входных данных трендовые карты, ГСР и кубы ЗД параметров, что обеспечивает учет концептуальных представлений и соответствие статистике по скважинам. Однако получаемая таким методом геологическая модель обеспечивала невысокую прогнозную способность (средняя ошибка в значении эффективной нефтенасыщенной мощности составляла от -10 до -30\%). Кроме того, результат был не стационарный.

- Indicator Kriging обеспечивает достаточно стационарный результат, однако не имеет возможности учета 1Д, 2Д, ЗД трендов.

- Truncated Gaussian Simulation (TGS) с использованием ГСР и 2Д трендов. В целом, имеет те же достоинства и недостатки, что и SIS.

- Моделирование дискретных параметров путем перевода их в непрерывные, построения куба при помощи Petrophysical Modelling (GRFS) и последующей «дискретизации» по отсечке. В целом, имеет те же достоинства и недостатки, что и SIS.

- Truncated Gaussian Simulation (TGS) с использованием ЗД трендов, построенных при помощи инструмента Trend Modelling с привлечением ГСР и 2Д трендов. Куб литологии строится с учетом фациальной принадлежности (для каждой фации используется свой ГСР).

Результат, полученный при помощи последнего описанного метода, отвечает всем требованиям, предъявляемым к геологической модели.

\section{Примеры}

Оценка прогнозной способности модели проводилась по следующему алгоритму:

- На основании опорных скважин (разведочный фонд) строилась геологическая модель.

- С полученной модели в точках пробуренных на настоящий момент пилотных стволов снимались «прогнозные» эффективные мощности.

- Строилась геологическая модель с учетом всего фонда, включая пилотные стволы.

- Рассчитывались абсолютные и относительные ошибки эффективных толщин пласта, строились гистограммы.

Ниже на рисунках 1 и 2 приведено сопоставление гистограмм невязок (в \% и м, соответственно) по двум методам - SIS и TGS с использованием 3Д трендов.

Для модели, построенной SIS, характерно систематическое занижение прогнозной эффективной толщины (до 70\% от фактической). Ширина диапазона составляет $90 \%$. Нулевая ошибка встречается всего в 14\% пробуренных скважин, средняя ошибка составляет -7,2 м.

При использовании TGS с 3Д трендами диапазон ошибок смещается в сторону нулевых значений и снижается на $10 \%$. Количество скважин с нулевой ошибкой увеличивается до $20 \%$. Средняя ошибка снижается до -2,0 м. 


\section{EAGE}

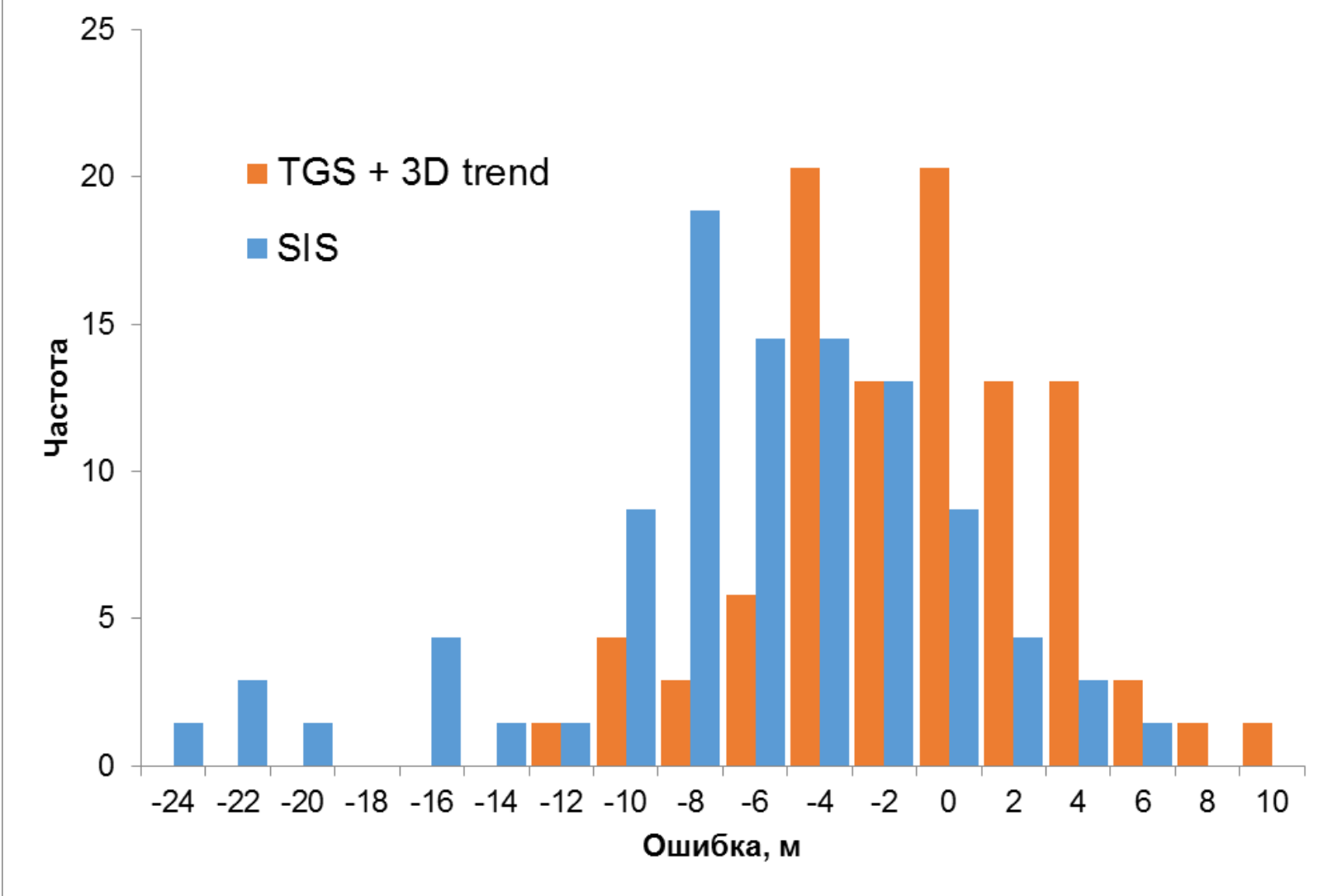

Рисунок 1 Сопоставление гистограмм невязок прогнозной и фактической эффективной мощности для моделей SIS и TGS+3D, м

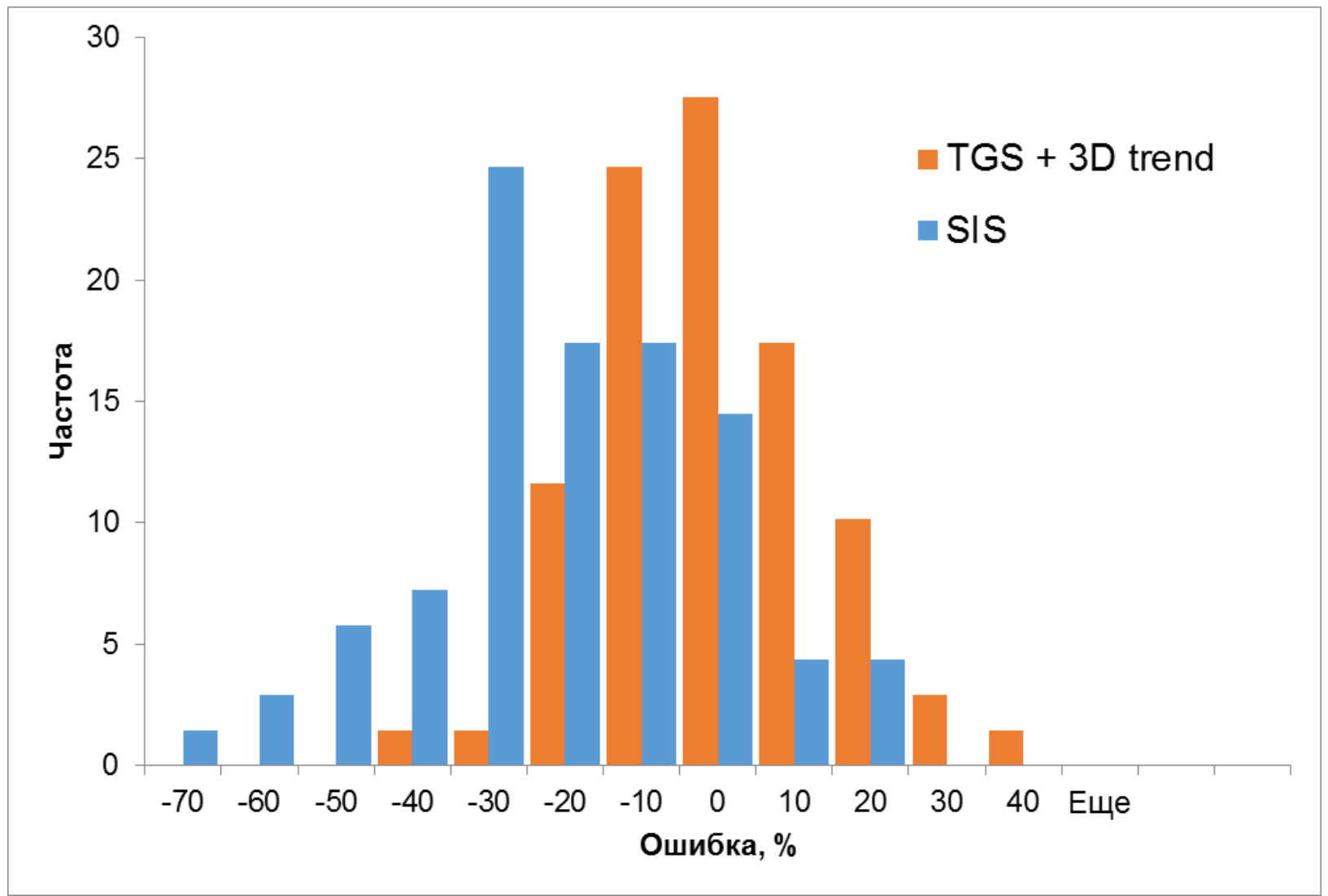

Рисунок 2 Сопоставление гистограмм невязок прогнозной и фактической эффективной мощности для моделей SIS и TGS+3D, \% 


\section{EAGE}

Стационарность модели проверялась следующим образом. На данных бурения субвертикальных скважин (разведочный фонд и пилотные стволы) была построена геологическая модель. Затем в исходные данные постепенно добавлялись горизонтальные стволы, анализировались изменения, происходящие в модели с появлением новой информации. Для метода TGS с 3Д трендами изменения фиксируются только в районе нового бурения (рисунок 3). Таким образом, обеспечивается стабильный

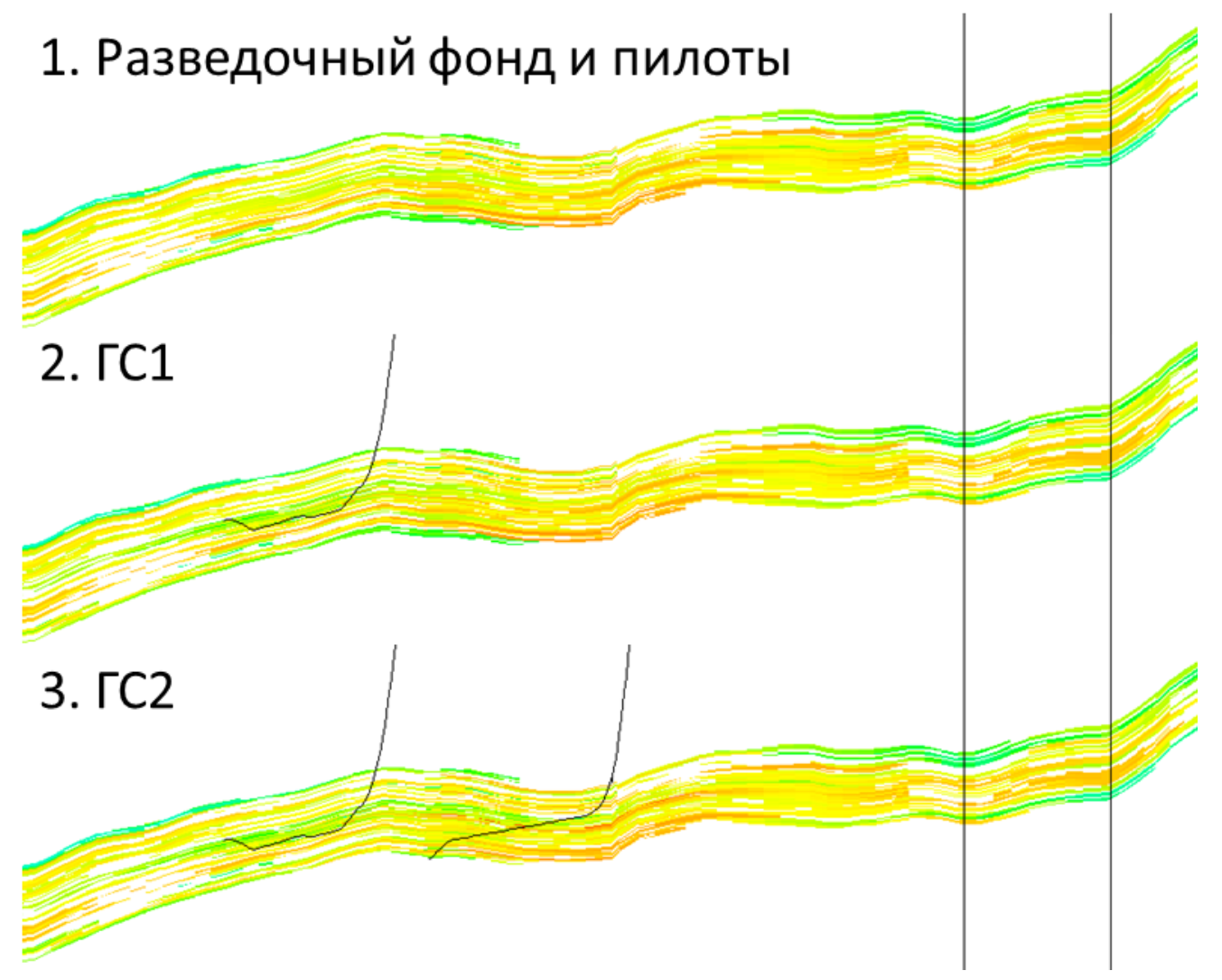

Рисунок 3 Пример влияния новой информации на геологическую модель

Bblвodbl

В настоящей работе освящены актуальные проблемы увеличения прогнозной способности и стационарности геологической модели, а также приведен эффективный метод ее решения построение при помощи TGS с ЗД трендами. Геологическая модель, построенная предлагаемым методом, отвечает всем предъявляемым к ней требованиям:

- Отвечает концептуальным представлениям о геологическом строении продуктивных пластов.

- Соответствует скважинным данным.

- Обладает достаточно высокой прогнозной способностью.

- Обеспечивает стационарный результат. 